Egyptian

Orthodontic Journal

\title{
EVALUATION OF SPONTANEOUS SPACE CLOSURE AFTER EXTRACTION OF THE FIRST PERMANENT MOLARS
}

\author{
Mahasen A. Taha ${ }^{1}$
}

ABSTRACT:

Objectives: The aims of this study were to evaluate changes in the position of the upper and lower premolars and second molars after first permanent molars "FPM $s$ " extraction, compare the changes in the position of the upper and lower teeth, evaluate the over eruption of the upper FPM in case of extraction of the lower one, and evaluate the midline shift in a unilateral extraction cases.

Materials: Fifty female patients with age range 8-10 (mean

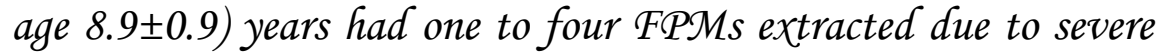
caries. Each case was followed up for two years after extraction. Where the sample was ended by 43 patients only. The angular and millimetric changes were documented by panoramic radiographs. Over eruption and midline shift were observed clinically.

Results: Both the upper and lower premolars showed distal tipping. However the lower tipped more than the upper. Also the lower second premolar showed more distal tipping than the lower first premolar. The lower second molar showed more mesial tipping than the upper one which moved more bodily. There were no over eruption of upper second molar or midline shift.

Conclusion: Extraction of the FPMs severely affected by caries is a good treatment alternative. Favorable spontaneous space closure by adjacent teeth could be expected without any intervention, if it is extracted prior to the eruption of the second molar.

Key Words: extraction, panoramic radiographs, midline shift.

1 - Lecturer, Department of Orthodontics, Faculty of Dentistry, Mansoura University. 
Egyptian

Orthodontic Journal

\section{INTRODUCTION}

First permanent molar teeth (FPMs) usually erupt when a child is six years of age. They are considered to be the most important permanent teeth, because of their role in the development and maintenance of the occlusion ${ }^{1,2}$.

It has been quoted as being the most caries prone tooth in the permanent dentition. This is probably as a result of its early exposure to the oral environment ${ }^{3,4,5,6,7}$. More than $50 \%$ of children over 11 years have some experience of caries in such teeth ${ }^{8}$.

A number of factors have to be considered when planning treatment for carious first permanent molars. These include, the restorative state of the tooth which depends on the degree of destruction of the crown, the extent to which the pulp has matured, the presence and /or absence and nature of pulpal damage, dental age of the patient, degree of crowding in the buccal and labial segments, the occlusal relationship, presence and condition of the other teeth, the attitude and wishes of the patient and parents ${ }^{9}$.

Treatment may range from restoring the tooth to maintain its pulpal vitality or devitalization and endodontic treatment, followed by provision of a crown, to early extraction ${ }^{1,2,4,7}$.

Some dentists may consider restoration of FPMs with extensive caries and pulpal symptoms during the mixed dentition stage. However, heavily restored teeth will enter the restorative cycle and may need extraction in later life. Extraction of the FPMs has been controversial for a long time. However in the latter half of the last century, orthodontists took a more positive attitude to extraction of $\mathrm{it}^{10}$.

Late extraction may lead to unfavorable occlusal changes if spaces are left unrestored ${ }^{9}$. In such cases consideration should be given to the extraction of these teeth during the mixed dentition stage $\mathrm{e}^{3}$.

The ideal time for extraction of the FPMs is before the eruption of the second permanent molar. When a radiographic evidence of early dentine calcification within the second molar root bifurcation .This is usually occurs at the chronological age of 8-9 years ${ }^{11}$. The second molar may erupt early and a good contact area relationship can be established with the second premolar. Most third molars will erupt with a tendency to 
early eruption, and most will establish a good contact area with the second molars ${ }^{12}$. Some distal drift of the premolars can also be expected at this stage, particularly if there is crowding in this region. ${ }^{13}$ The response of the teeth varied with the age of the patient at the time of extraction. It also varied in the maxilla than in the mandible. ${ }^{14}$

The aims of this study were to evaluate post extraction movement of adjacent teeth "first and second premolars and second permanent molar", compare the movement of the teeth in the upper and lower arches, evaluate midline shift in unilateral extraction cases, and evaluate overeruption of the upper FPMs after extraction of the opposite one.

\section{MATERIALS AND METHODS}

A sample of 50 female patients with age range from 8 to 10 (mean age $8.9 \pm 0.9$ ) years who had one to four FPMs extracted due to sever caries and poor prognosis were selected from Dental Department at AL-Hada Military Hospital, Taif region, Saudia Arabia ( Table 1).At the end of the follow up period, the sample was based on 43 patients, where 7 patients were not available.

Table (1): Distribution of the sample at the time of extraction

\begin{tabular}{|l|c|c|c|c|}
\hline \multicolumn{1}{|c|}{ Number of extracted molars } & Lower & Upper & Lower and upper & Total \\
\hline One molar & 15 & 9 & - & 24 \\
\hline Two molars & 9 & 7 & - & 16 \\
\hline Tree molars & & & 6 & 6 \\
\hline Four molars & & & 4 & 4 \\
\hline Total & 24 & 16 & 10 & 50 \\
\hline
\end{tabular}

The inclusion criteria for extraction were; all the patients had one to four badly destroyed FPMs with poor prognosis which indicates extraction of these teeth, the patients did not have any orthodontic treatment, dental Class I molar relation with accepted profile, the patients had bilaterally unerupted second molars, and good quality pre-extraction and post-extraction panoramic x-rays.

Exclusion criteria for extraction therapy were general spacing and /or agenesis of permanent teeth in the quadrant concerned with exception of 
third molars. It was not possible to judge if the child had third molars or not before the age of nine approximately. ${ }^{15}$

The post-extraction space closure was evaluated from the panoramic radiographs. Which were taken for all the patients before or immediately after the extraction of FPMs and two years after extraction.

The reference plane constructed in this study was a modification of the midline reference plane (MRP). ${ }^{16}$ The nasal septum and the anterior nasal spine (ANS) were traced and bisected. A perpendicular line was drawn to this midline bisector that extended through the palatal shadow bilaterally. This constructed plane was termed the horizontal reference plane (HRP). A perpendicular line was drawn to the (HRP) at the anterior nasal spine and called vertical reference plane (VRP). The outline of the second permanent molars and first and second premolars and their long axes were drawn on the tracing sheet. The long axis of the second molar was traced from the midocclusal point through the midpoint of the root bifurcation.

\section{The following measurements were made, as shown in Figure 1:}

1- The outer angles formed by the second molar, first and second premolars axes to the horizontal reference plane (HRP). ${ }^{17}$

2- The horizontal millimetric distance drawn perpendicular from the mesial contact point of the premolars and second molars ( $\mathrm{ms}$ and $\mathrm{mi}$ ) to the vertical reference plane (VRP).

3- Midline shift was observed clinically on the patients.

4- Over eruption of opposing FPMs was observed clinically by visual inspection.

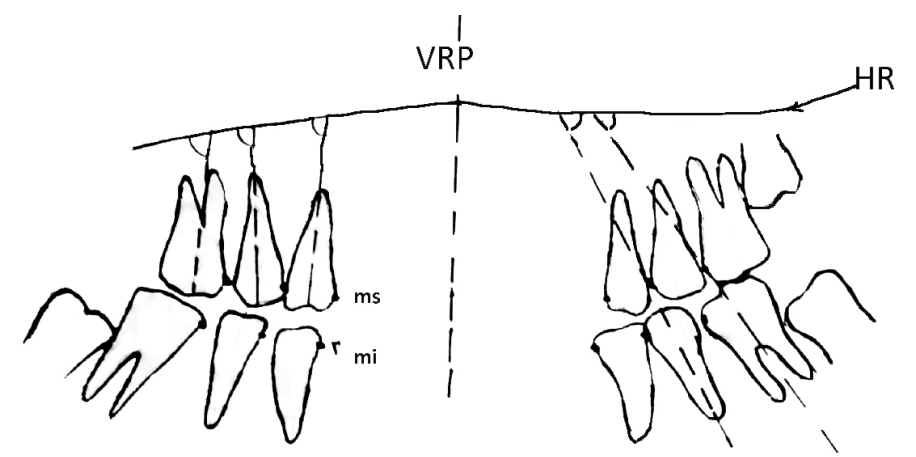

Fig. 1: showing planes and angles. 
All measurements were calculated and analyzed using the SPSS statistical program $\{$ Chicago, IL $\}$.Descriptive statistics including means and standard deviations of measurements and their changes before and after extraction was obtained. Then, $t$ test was used to determine the significance difference in the changes of the measurements between the maxillary and mandibular teeth .Significance for the statistical test was predetermined at $\mathrm{P} \leq 0.05$

\section{RESULTS}

Means, standard deviations and the significance of extraction changes of mandidular teeth measurements are reported in Table 2.

Measurements of the maxillary teeth before and after extraction are presented in Table 3. A comparison of the mean changes between mandibular and maxillary teeth and the significance of difference between them are presented in Table 4 and Figure 2.

\section{Changes in the mandibular teeth position:}

First and second premolars showed significant distal tipping, as the angle of their long axes with the HRP increased significantly $(\mathrm{P}=0.003$, $\mathrm{P}=0.001$ respectively). Furthermore, there were significant increase in horizontal millimetric distances mi/VRP ( $\mathrm{P}=0.001, \mathrm{P}=0.000$ respectively). While the second molar showed significant mesial tipping $(\mathrm{P}=0.001)$ and mesial shifting $(\mathrm{P}=0.000)$.

\section{Changes in the maxillary teeth position:}

There were significant distal tipping of first and second premolars $(\mathrm{p}=0.003, \mathrm{P}=0.002$ respectively) and distal shifting as evidenced by the increase in horizontal distance $\mathrm{ms} / \mathrm{VHP}(\mathrm{P}=0.002, \mathrm{P}=0.001$ respectively). However there was no significant mesial tipping of the second molar. Where the angle between its long axis and the horizontal plane increased only by $1.46^{\circ} \pm 2.74^{\circ}(\mathrm{P}=0.414)$. While it showed a significant mesial shifting, The ms/VRP was significantly decreased $(\mathrm{P}=0.000)$. 


\section{Comparing the changes in the position of the upper teeth with the lower teeth:}

There was a significant difference in the inclination between the mandibular and maxillary teeth. where the mandibular first premolar tipped distally $7.88^{\circ} \pm 6.52^{\circ}$ but the maxillary first premolar tipped distally $3.66^{\circ} \pm 2.92^{\circ}(\mathrm{P}=0.000)$. The mandibular second premolar tipped distally $9.94^{\circ} \pm 8.17^{\circ}$, while the maxillary second premolar tipped distally $4.80^{\circ} \pm 4.70^{\circ}(\mathrm{P}=0.000)$. Also the mandidular second molar tipped mesially $7.88^{\circ} \pm 5.90^{\circ}$ but the maxillary second molar tipped mesially only $1.46^{\circ} \pm 2.74^{\circ}(\mathrm{P}=0.000)$. However there were no significant difference in the horizontal millimetric measurements between the upper and lower teeth.

Table 2: Changes in the measurements of the lower teeth.

\begin{tabular}{|l|c|c|c|c|}
\hline \multicolumn{1}{|c|}{ Tooth } & Pre-extraction & Post-extraction & t & p value \\
\hline First premolar \{\}$^{\circ}$ & $80.5 \pm 8.72^{\circ}$ & $88.38 \pm 7.6^{\circ}$ & -3.51 & $.003^{*}$ \\
\hline First premolar $\{\mathbf{m m}\}$ & $14.62 \pm 1.45 \mathrm{~mm}$ & $17.68 \pm 1.62 \mathrm{~mm}$ & -6.78 & $.000^{*}$ \\
\hline Second premolar \{\}$^{\circ}$ & $75.5 \pm 6.48^{\circ}$ & $85.44 \pm 9.17^{\circ}$ & -4.14 & $.001^{*}$ \\
\hline Second premolar $\{\mathbf{m m}\}$ & $18.58 \pm 1.87 \mathrm{~mm}$ & $23.75 \pm 2.08 \mathrm{~mm}$ & -7.53 & $.000^{*}$ \\
\hline Second molar \{\}$^{\circ}$ & $65.38 \pm 4.01^{\circ}$ & $57.5 \pm 5.64^{\circ}$ & 5.67 & $.000^{*}$ \\
\hline Second molar $\{\mathbf{m m}\}$ & $38.87 \pm 3.30 \mathrm{~mm}$ & $31.78 \pm 2.64 \mathrm{~mm}$ & 6.98 & $.000^{*}$ \\
\hline
\end{tabular}

*Significant at $\mathrm{P} \leq 0.05$

Table 3: changes in the measurements of the upper teeth.

\begin{tabular}{|l|l|l|l|l|}
\hline \multicolumn{1}{|c|}{ Tooth } & Pre-extraction & Post-extraction & \multicolumn{1}{c|}{ t } & p value \\
\hline First premolar \{\}$^{\circ}$ & $91.6 \pm 2.66^{\circ}$ & $87.93 \pm 5.06^{\circ}$ & 3.62 & $.003^{*}$ \\
\hline First premolar $\{\mathbf{m m}\}$ & $16.5 \pm 2.27 \mathrm{~mm}$ & $19.21 \pm 1.62 \mathrm{~mm}$ & -3.76 & $.002^{*}$ \\
\hline Second premolar \{\}$^{\circ}$ & $90.2 \pm 4.42^{\circ}$ & $85.4 \pm 5.06^{\circ}$ & 3.94 & $.002^{*}$ \\
\hline Second premolar $\{\mathbf{m m}\}$ & $21.92 \pm 3.14 \mathrm{~mm}$ & $25.21 \pm 2.83 \mathrm{~mm}$ & -4.21 & $.001^{*}$ \\
\hline Second molar \{\}$^{\circ}$ & $86.2 \pm 7.91^{\circ}$ & $87.66 \pm 7.34^{\circ}$ & -.842 & .414 \\
\hline Second molar $\{\mathbf{m m}\}$ & $41.78 \pm 4.91 \mathrm{~mm}$ & $34.28 \pm 4.71 \mathrm{~mm}$ & 4.82 & $.000^{*}$ \\
\hline
\end{tabular}

* Significant at $\mathrm{P} \leq 0.05$ 
Table 4: Comparing the changes in the upper and lower teeth.

\begin{tabular}{|l|c|c|c|c|}
\hline \multicolumn{1}{|c|}{ Tooth } & Lower teeth & Upper teeth & T & p value \\
\hline First premolar \{\}$^{\circ}$ & $7.88 \pm 6.52^{\circ}$ & $-3.66 \pm 2.92^{\circ}$ & 4.38 & $0.000^{*}$ \\
\hline First premolar $\{\mathrm{mm}\}$ & $3.06 \pm 1.80 \mathrm{~mm}$ & $2.71 \pm 2.60 \mathrm{~mm}$ & 0.420 & 0.678 \\
\hline Second premolar \{\}$^{\circ}$ & $9.94 \pm 8.17^{\circ}$ & $-4.80 \pm 4.70^{\circ}$ & 5.160 & $0.000^{*}$ \\
\hline Second premolar $\{\mathrm{mm}\}$ & $5.16 \pm 2.74 \mathrm{~mm}$ & $3.28 \pm 2.92 \mathrm{~mm}$ & 1.815 & 0.080 \\
\hline Second molar \{\}$^{\circ}$ & $-7.88 \pm 5.90^{\circ}$ & $1.46 \pm 2.74^{\circ}$ & -4.249 & $0.000^{*}$ \\
\hline Second molar $\{\mathrm{mm}\}$ & $-7.12 \pm 4.08 \mathrm{~mm}$ & $-7.50 \pm 5.81 \mathrm{~mm}$ & 0.207 & 0.838 \\
\hline
\end{tabular}

* Significant at $\mathrm{P} \leq 0.05$

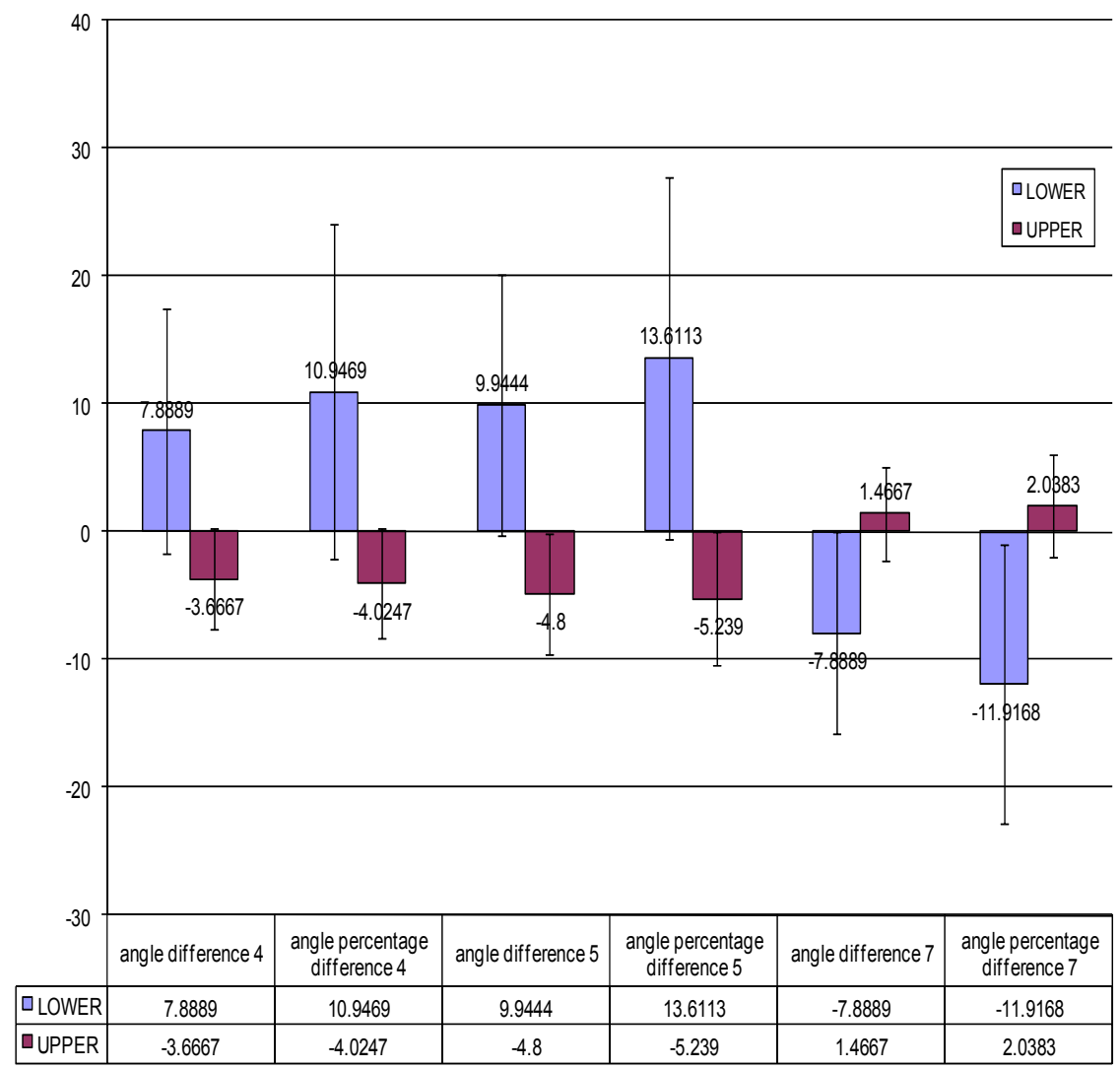

Fig. 2: comparing angle measurements between upper and lower teeth. 


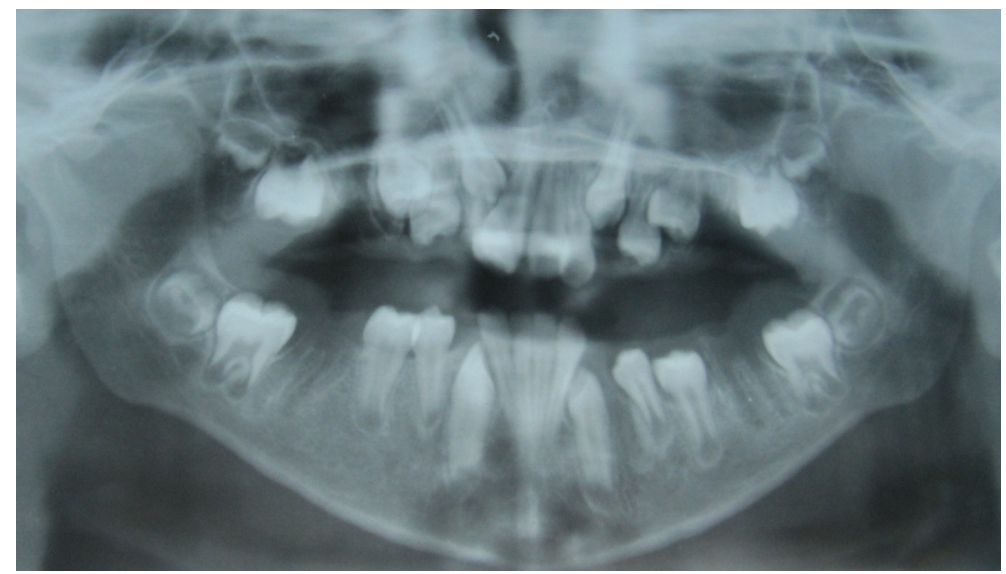

Fig. 3 (a): tooth positioning in a girl having all FPMs extracted at the age of 9.9 years.

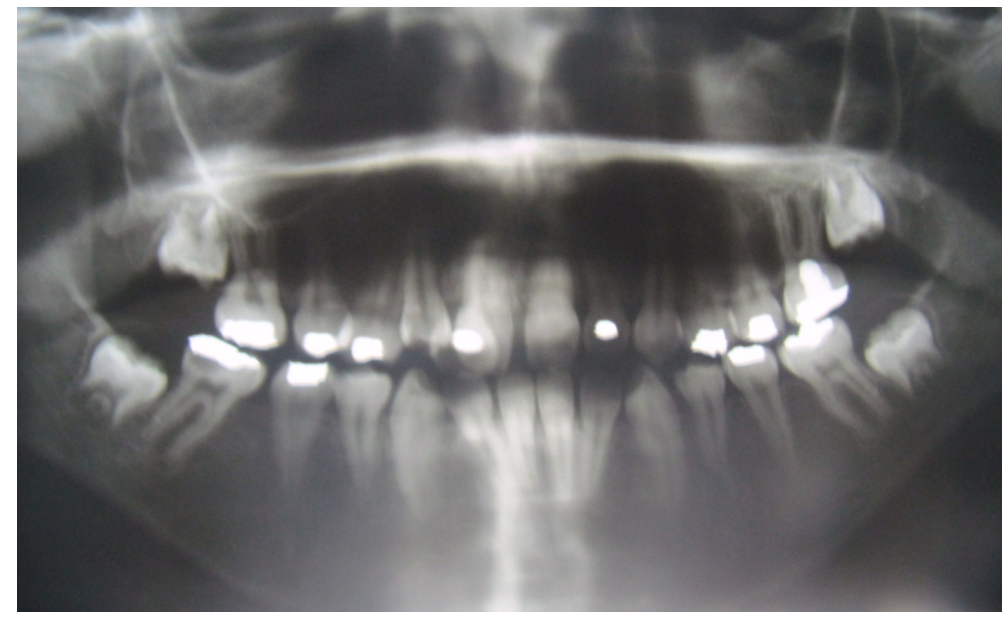

Fig. 3 (b): two years after extraction.

\section{DISCUSSION}

In this study changes in the teeth position were evaluated by using panoramic radiographs. Measurements of the posterior teeth angulation on lateral cephalograms, as seen in previous studies ${ }^{18,19,20,21,22}$ may be biased because of differences in angulation between superimposed images. This problem can only be overcomed if measurements are made on 60 degree head films of the left and right sides ${ }^{23}$. However other studies ${ }^{24,25}$ 
have shown that panoramic is a reliable indicator in evaluating the posterior teeth positions. So it was used in this study. The palatal plane was used as a horizontal reference plane .It is more stable during growth. Even if such changes had taken place, they were likely to be small during the relatively short observation period ' 2 years', ${ }^{26}$

The results of the present study revealed that, upper and lower premolars showed distal shifting. This could be explained by the extraction of FPMs in most cases '39 patients" before the eruption of the premolars. Lower premolars showed more distal inclination than the upper premolars $\{\mathrm{P}=0.000\}$. This may be due to faster space closure and distal shifting of premolars in the maxilla than in the mandible. This finding was in agreement with other studies ${ }^{13,17,27,28}$.But it contradict with one study ${ }^{29}$ which found that the location of the FPMs extraction(maxillary or mandibular) has no statistical influence on the horizontal migration of premolars . This is due to their sample which came from a far wider age range " $5-18$ ". Also they did not use any angular measurements but only evaluated the space closure by visual inspection and graduated probe. But in horizontal millimetric measurements there was no significant difference between the upper and lower premolars.

In the mandible the difference in the degree of distal tipping between the first and second premolars (first premolar was $7.88^{\circ} \pm 6.52^{\circ}$ second premolar was $9.94^{\circ} \pm 8.17^{\circ}$ ) was greater than in the maxilla (first premolar $3.66^{\circ} \pm 2.92^{\circ}$, second premolar $4.80^{\circ} \pm 4.70^{\circ}$ ) and in some cases was accompanied with spacing in the lower premolar area. This was matched with other studies ${ }^{13,28}$.

The lower second molar showed more mesial tipping than the upper one ' $\mathrm{P}=0.000$ '. While in millimetric horizontal measurements, there was no significant difference between them $\mathrm{P}=0.838$. This may be due to that, the upper second molar is often quite high and develops with a distal angulation and only need to alter their eruption pathway slightly more mesially to allow them to erupt almost into the first molar socket. While the lower second molar has much more vertical path of eruption, so when the FPM extracted it tipped mesially .This finding was in agreement with other studies ${ }^{13,17,27,28,29,30}$ 
A clinical dilemma is if compensating extraction of an opposing healthy first permanent molar or balancing extraction of contralateral healthy first molar have to be carried out .In this study, uncompensated and unbalanced extractions were performed .In spite of this, there was a good spontaneous occlusal development. There was no overeruption of the opposing upper FPMs when the lower FPMs were extracted. Also no midline shift when a unilateral extraction was performed. This could be due to the young age of the sample and/or the assessment of the overeruption by visual inspection without using any measurements. This finding was also compatible with other studies, ${ }^{13,17}$ but was in conflict with that of at least two previous studies ${ }^{29,31}$. In the first one they found overeruption in $12 \%$ of their sample ,in the patients from older age groups (15-16 years) .The second study found overeruption of the opposing tooth was the main consequence of loss of FPMs. This may be due to their longer follow up period. Therefore, you can assume that compensating and balancing extraction are not always beneficial when extracting FPMs especially at young age.

\section{CONCLUSIONS}

From the results of this study, the following conclusions can be drawn:

1- When FPMs extracted before the eruption of the second molars and premolars. The space is closed by distal shifting of premolars and mesial shifting of second molars.

2- The lower teeth showed more tipping than the upper teeth, especially the second premolar and second molar.

3- Compensating and/or balancing extraction is not always beneficial when extracting FPMs.

\section{REFERENCES}

1- Raducanu, AM. Pedodontics, Bucharest:Cerma;2002:pp.141-149.

2- Druo JP. The six years tooth, crossroad of all dangers. Quintessence du Congress de l'Association Dentaire Francaise, 1998. Accessed (2009 Apr 25\} at:http://www.adf.asso.fr/cfm/site/thesaurus/detail_conference.cfm?rubrique origine $=47$ and conference $=45 / 1$ 
3- Albadri S, Zaitoun H, McDonnell ST, Davidson LE : Extraction of first permanent molar teeth : results from three dental hospitals. British Dental Journal 2007;203: 408-409.

4- Bratu E: Pedodontic Practice. $3^{\text {rd }}$ ed.timisoara,Romania:University Horizons;2005:pp.281-291.

5- Chafaie A, Portier R : Restoration of the six years tooth: problems and solutions. Papers of the L'Association Dentaire Francaise 1999;1(4):24-35.

6- Davies SJ, Gray R JM, MackieI C: Good occlusal practice in children's dentistry. British Dental Journal 2001;191:655-659.

7- Shugars DA,Bader JD,Phillips SW Jr, White BA, Brantley CF : The consequences of not replacing a missing posterior tooth. Journal of the American Dental Association 2000; 131:1317-1323.

8- Todd JE, Dodd T: Children dental health in the United Kingdom. London:Office of Population Censuses and surveys, 1983.

9- Gill DS, Lee RT, and Tredwin CJ : Treatment planning for the loss of first permanent molars. Dental Update 2001; 28:304-308.

10- Williams JK, Gowans AJ : Hypomineralized first permanent molars and the orthodontist .Eur J Pediatr Dent 2003; 4:129-132.

11- Thunold K: Early loss of the first molars 25 years later .Trans Eur Orthod Soc $1970 ; 349-365$.

12- Williams R, Hosila L: The effects of different extraction sites upon incisor retraction. Am J Orthod 1976; 69:388-410.

13- Plint DA: The effect on the occlusion of the loss of one or more first permanent molar. Trans Eur Orthod Soc 1970; 329-336.

14- Sandler PJ, Atkinson R, Murry AM: For four sixes. Am J Orthod Dentofacial Orthop 2000;130:634-638.

15- Jalevik B, Moller M: Evaluation of spontaneous space closure and development of permanent dentition after extraction of hypomineralized permanent first molars. International Journal of Paediatric Dentistry 2007;17:328-335. 
16- Elsey MJ, and Rock WP: Influence of orthodontic treatment on development of third molars . B J Oral Maxillo Fac Surg 2000;38:350-353.

17- Suruchi J, and Ashima V : Influence of first premolar extraction on mandibular third molar angulation. Angle Orthod 2009;79 (6):1143-1148.

18- Capell J: Mandibular growth and third molar impaction in extraction cases . Angle Orthod 1991;61(3):223-229.

19- Erdem D, Ozdiler E, ToygarMenikoglu U, and Baspinar E : Third molar impaction in extraction cases treated with Begg technique.Eur J Orthod 1998;20:263-270.

20- Kim TW, Årtun J, Behbehani F, and Artese F: Prevalence of third molar impaction in orthodontic patients treated non extraction and with extraction of 4 premolars. Am J Orthod Dentofacial Orthop 2003;132(2):138-145.

21- Årtun J, Thalib L, and little RM: Third molar angulations during and after treatment of adolescent orthodontic patients. Eur J Orthod 2005;27:590-596.

22- Behbehani F, Årtun J, and Thalib L: Prediction of mandibular third molar impaction in adolescent orthodontic patients. Am J Orthod Dentofacial Orthop 2006;130:47-55.

23- Richardson ME: The early developmental position of the lower third molar relative to certain jaw dimensions. Angle Orthod 1970; 40:226-230.

24- Olive R J, and Basford KE: Transverse dentoskeletal relationships and third molar impaction. Angle Orthod 1981;51: 41-47.

25- Larheim T A, and Svanaes DB: Reproducibility of rotational panoramic radiography -mandibular linear dimensions and angles. Am J Orthod Dentofacial Orthop 1986;90:45-51.

26- Nanda RS: Reappraising Wits Readers forum. Am J Orthod Dentofacial Orthop 2004;125:18A.

27- Wilkinson AA: The permanent first molar again. Brit Dent J 1940; 8:269-288. 
Egyptian

Orthodontic Journal

28- Salzman A J: The rationale of extraction as an adjunct to orthodontic mechanotherapy and sequelae of extraction in the absence of orthodontic guidance. AJO 1945; 31:181-202.

29- Raducanu AM, Feraru V, Raducanu MA, and Herteliu C: Prevalence of loss of permanent molars in a group of Romanian children and adolescents. Romanian Dentistry Journal 2009;8 (3):3-10.

30- Thilander B, and Skagius S: Orthodontic sequelae of extraction of permanent first molars. A longitudinal study. Rep Congr Eur Orthod Soc 1970; 429-442.

31- Arias DP, Zaldivar XBB, Gonzalez IJN Perez OR: Loss of the first permanent molar in children between 7 and13 years old. Accessed (2009 may 28) at :http//www.amc.sld.cu/amc/2008/v12n5/amc08508.htm 